\title{
Local anthropogenic impact on particulate elemental carbon concentrations at Summit, Greenland
}

\author{
G. S. W. Hagler ${ }^{1}$, M. H. Bergin ${ }^{1,2}$, E. A. Smith ${ }^{1}$, M. Town ${ }^{3}$, and J. E. Dibb ${ }^{4}$ \\ ${ }^{1}$ School of Civil and Environmental Engineering, Georgia Institute of Technology, Atlanta, GA 30332, USA \\ ${ }^{2}$ School of Earth and Atmospheric Sciences, Georgia Institute of Technology, Atlanta, GA 30332, USA \\ ${ }^{3}$ Department of Atmospheric Sciences, University of Washington, Box 351640, Seattle, WA 98195-1640, USA \\ ${ }^{4}$ Climate Change Research Center, Institute for the Study of Earth, Oceans, and Space, University of New Hampshire, \\ Durham, NH 03824, USA
}

Received: 7 December 2007 - Published in Atmos. Chem. Phys. Discuss.: 25 January 2008

Revised: 23 April 2008 - Accepted: 23 April 2008 - Published: 9 May 2008

\begin{abstract}
Summit, Greenland is a remote Arctic research station allowing for field measurements at the highest point of the Greenland Ice Sheet. Due to the current reliance on diesel generators for electricity at Summit, unavoidable local emissions are a potential contamination threat to the measurement of combustion-related species in the air and snow. The effect of fossil-fuel combustion on particulate elemental carbon (EC) is assessed by a combination of ambient measurements $(\sim 1 \mathrm{~km}$ from the main camp), a series of snow pits, and Gaussian plume modeling. Ambient measurements indicate that the air directly downwind of the research station generators experiences particulate absorption coefficient (closely related to EC) values that are up to a factor of 200 higher than the summer 2006 non-camp-impacted ambient average. Local anthropogenic influence on snow EC content is also evident. The average EC concentration in 1-m snow pits in the "clean air" sector of Summit Camp are a factor of 1.8-2.4 higher than in snow pits located $10 \mathrm{~km}$ and $20 \mathrm{~km}$ to the north ("downwind") and south ("upwind") of the research site. Gaussian plume modeling performed using meteorological data from years 2003-2006 suggests a strong angular dependence of anthropogenic impact, with highest risk to the northwest of Summit Camp and lowest to the southeast. Along a transect to the southeast (5 degree angle bin), the modeled frequency of significant camp contribution to atmospheric EC (i.e. camp-produced EC > summer 2006 average
\end{abstract}

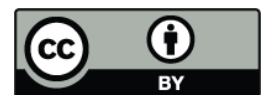

Correspondence to: G. S. W. Hagler (gayle.hagler@gatech.edu)
EC) at a distance of $0.5 \mathrm{~km}, 10 \mathrm{~km}$, and $20 \mathrm{~km}$ is $1 \%, 0.2 \%$, and $0.05 \%$, respectively. According to both the snow pit and model results, a distance exceeding $10 \mathrm{~km}$ towards the southeast is expected to minimize risk of contamination. These results also suggest that other remote Arctic monitoring stations powered by local fuel combustion may need to account for local air and snow contamination in field sampling design and data interpretation.

\section{Introduction}

Since its inception in 1989, the United States National Science Foundation research station at the highest point of the Greenland Ice Sheet $\left(72^{\circ} \mathrm{N}, 38^{\circ} \mathrm{W}\right.$, elevation $3200 \mathrm{~m}$, website address: www.geosummit.org), "Summit Camp", has been an extremely valuable research site. The immense effort placed into providing electricity, communications, and shelter at this remote location has paid off in access to rare field measurements supporting numerous scientific disciplines (e.g. glaciology, atmospheric chemistry, and paleoclimatology). While many field measurements at Summit are naturally immune to post-1989 camp activity at Summit station (e.g. deep ice core studies), numerous research studies involve measurements that may be vulnerable to camp emissions such as atmospheric monitoring or sampling of shallow snow pits. Impacts on the local environment by the Summit research site likely include a modification in nearby snow accumulation as camp structures alter natural drifting patterns, the introduction of foreign bacteria by visiting researchers

Published by Copernicus Publications on behalf of the European Geosciences Union. 
and their related refuse, and the contamination of the local environment due to emissions from camp fossil fuel burning (camp generators, heavy equipment, snowmobiles, and aircraft).

The focus of our research team's effort at Summit Camp was to measure carbonaceous particulate matter (organic and elemental carbon) in the air and snow. These species are of interest as markers of natural and anthropogenic emissions reaching the Greenland Ice Sheet (e.g. fossil fuel combustion and biomass burning), both in ambient sampling and as a paleorecord of previous source activity. While carbonaceous particulate species have been measured in several past field studies at Summit, no thorough investigation into the potential contamination from camp fossil fuel combustion has taken place. Although Summit Camp seeks to minimize human impacts on the pristine environment (e.g. sleeping in unheated tents during the summer season), currently it is necessary to operate two diesel generators (burning modified Jet A-1 fuel) for electricity at all times, diesel-powered heavy equipment to groom an aircraft "ski-way" and dig snow for water use, and gasoline-powered snowmobiles for dragging heavy loads. To protect the designated "clean air" sector located south of camp, staff and researchers cease vehicular use during northerly winds. However, the camp generators are in continuous use and intermittent (every 2-3 weeks during the spring to summer and every $2-3$ months during late-summer to early-spring) supply aircraft arrivals occur regardless of wind direction. As these emitting sources could potentially contaminate our atmospheric sampling for organic and elemental carbon, protective measures were integrated into our atmospheric sampling protocol during the field season (cessation of integrated filter sampling during air traffic and ongoing sector control at all other times). In addition, given that elemental carbon (EC) is expected to be a stable tracer of local combustion emissions, six snow pits were sampled for EC and Gaussian plume modeling was performed to better understand the footprint of camp contamination. While this study is focused primarily on carbonaceous species, this research is expected to be applicable to other atmospheric species of interest that may be impacted by camp emissions at Summit, Greenland.

\section{Methods}

Extensive sampling of the air and snow for particulate carbonaceous species took place at a research site located approximately $1 \mathrm{~km}$ from Summit, Greenland during the summer of 2006. The field methods are described by Hagler et al. (2007a,b), so the sampling procedures will be only briefly discussed. Atmospheric sampling included near-real-time (minutes to hours) measurement of the aerosol absorption coefficient $\left(\sigma_{\text {ap }}\right)$ using a Particle Soot Absorption Photometer (PSAP). Using a calculated mass absorption coefficient of $24 \mathrm{~m}^{2} \mathrm{~g}^{-1}$ (Hagler et al., 2007b), $\sigma_{\text {ap }}$ was converted to an estimated EC concentration.

In addition to the ongoing atmospheric sampling for $\sigma_{\mathrm{ap}}$, a sector control system was put in place to flag time periods when wind patterns created a potential contamination threat from camp emissions. This system included wind speed and direction sensors (Campbell Scientific Inc., RM Young Wind Sentry Set, 03001-L), a datalogger (Campbell Scientific Inc., CR200 Datalogger), and two modified power strips that provided the capability to shut off time-integrated atmospheric filter sampling. Under periods of stagnation (wind speed $<0.5 \mathrm{~m} \mathrm{~s}^{-1}$ ) or during northerly winds that may transport camp emissions to our southerly research site, the sector control system would shut off integrated samples and assign a "flag" variable the value of 0 (flag=1 during "on" periods). The sector control program ran and reacted every 10 minutes (a compromise between the need for a short response time and the desire to minimize the cycling off/on of sampling pumps).

The potential impact of Summit camp on snow-phase EC was investigated through a series of six 1-m snow pits that were dug and sampled over a two-week period in the month of July. Two snow pits were co-located in the "clean air" region of Summit (approximately $0.5 \mathrm{~km}$ to the south), a region that has additional protection of reduced camp vehicular emissions during northerly winds. The remaining four snow pits were located at 10 and $20 \mathrm{~km}$ to the north and south of Summit. Each snow pit was sampled at $20 \mathrm{~cm}$ increments (5 total layers) for particulate elemental and organic carbon (Hagler et al., 2007a). Duplicates were sampled at two layers in each snow pit.

To better understand the impact of Summit camp activity on the local atmosphere and to interpret our snow pit samples, a Gaussian plume model was applied to estimate the regional footprint of Summit camp contamination. The camp emission rate of EC was estimated by assessing concentration spikes in $\sigma_{\text {ap }}$ that occurred throughout the summer, ranging $\sim 2-30 \mathrm{Mm}^{-1}$ (compared with the summertime average of $0.15 \mathrm{Mm}^{-1}$ ). A moderate spike of $14.5 \mathrm{Mm}^{-1}$ that occurred on 10 July was selected as a "best guess" for its midrange concentration and the absence of flight traffic on that day, with the source emission rate calculated assuming this was a centerline plume concentration intersecting the satellite ambient sampling station located $1 \mathrm{~km}$ from camp. The measured $\sigma_{\text {ap }}$ was converted to an EC concentration using a previously calculated mass absorption efficiency coefficient of $24 \mathrm{~m}^{2} \mathrm{~g}^{-1}$ (Hagler et al, 2007b), and a camp emission rate of EC $(Q)$ was back-calculated using the standard Gaussian plume model with ground reflection using Eqs. (1)-(4).

$C(x, 0,0)=\frac{Q}{\pi u \sigma_{y} \sigma_{z}} \exp \left[-\frac{H^{2}}{2 \sigma_{z}^{2}}\right]$

Where: $x=1(\mathrm{~km})$

$T H=0.01745(18.3330-(1.8096) \ln (x))$ 
a.

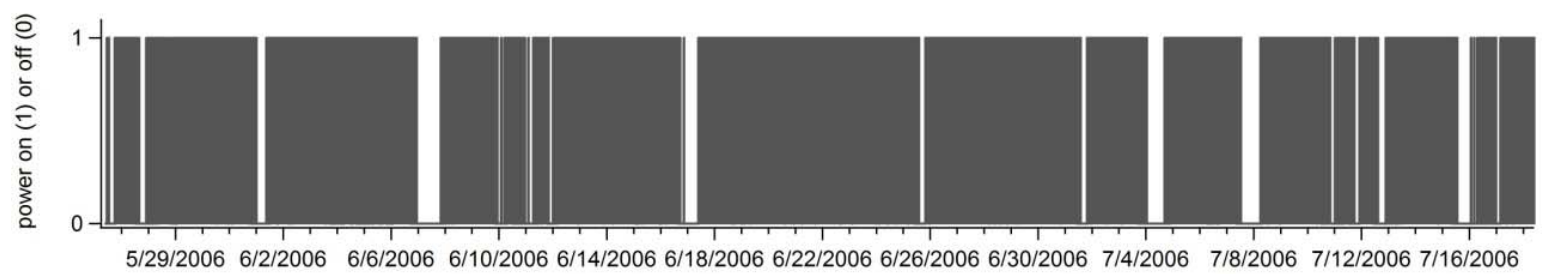

b.

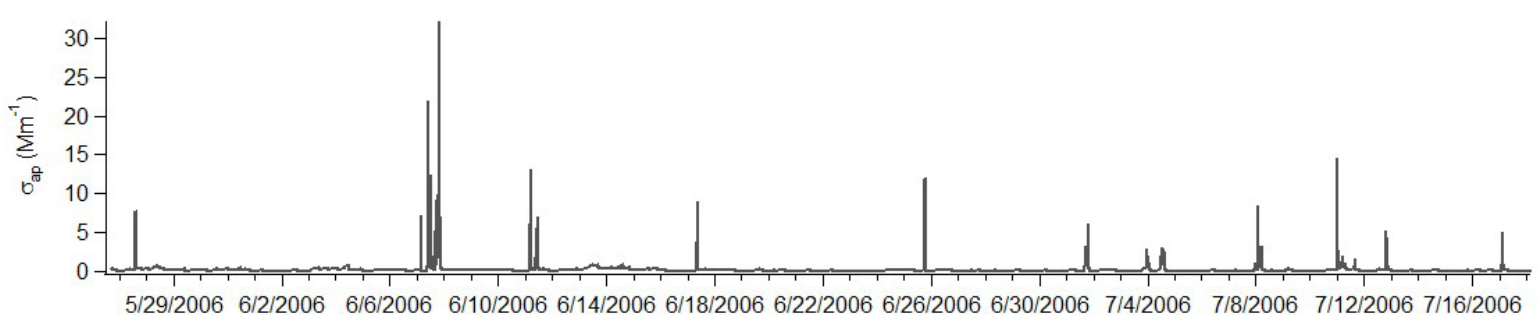

Fig. 1. Sector control power on/off (a) and the raw absorption coefficient data (b).

$\sigma_{y}=465.11628(x) \tan (T H)$

$\sigma_{z}=453.85(x)^{2.1166}$

Equations for the dispersion coefficients, $\sigma_{y}$ and $\sigma_{z}$, are from the US EPA Industrial Source Complex (ISC3) Dispersion Models (US EPA OAQPS, 1995) for the Pasquill Stability Category B (moderate wind speed, daytime conditions). Assuming ground-level emissions $(H=0)$ and inputting the measured wind velocity $(u)$ at the time of the spike, $Q$ was estimated to be $8.64 \times 10^{7} \mathrm{ng} \mathrm{s}^{-1}$. It should be noted that the value of $Q$ is a best estimate, relying on assumptions of a representative spike in $\sigma_{\mathrm{ap}}$, that the mass absorption efficiency value is accurate, and that the case of ground reflection applies. While there is significant uncertainty in the estimated value of $Q$, the meteorology data are measured values and strengthen the conclusions about relative contamination risk over various wind angles and distance from camp.

Keeping the emissions rate and the stability category (B) constant, the Gaussian plume model was calculated over the past four years (2003-2006) using available meteorology data collected by ETH Zürich, Institute for Atmospheric and Climate Science (hourly 1-m wind speed and direction at Summit Camp) and binning wind angles into 15 degree increments. Given that the wind sensors performed poorly during extremely low temperatures $\left(T<-35^{\circ} \mathrm{C}\right)$, only limited meteorology data were available during the winter season of each year. For each meteorology data point, the camp plume's centerline concentration was calculated at distances $(x)$ from Summit ranging up to $30 \mathrm{~km}$, at $0.5 \mathrm{~km}$ increments. For the remainder of the compass angle bins that did not have a plume from camp at that time instance, the concentration value was set to 0 . Final results were expressed as a predicted concentration per time, angle, and distance.

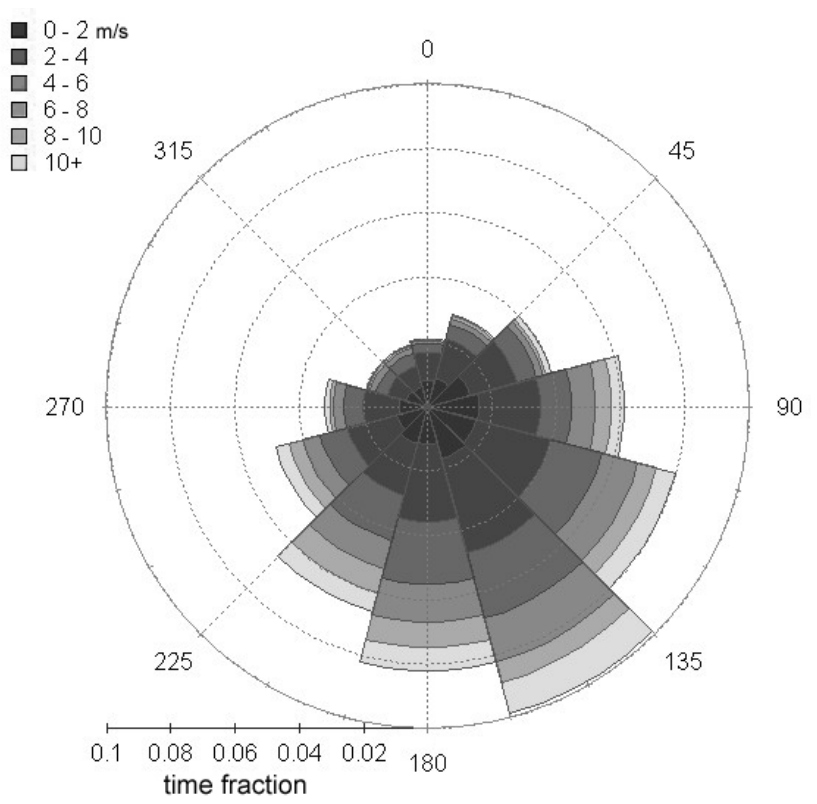

Fig. 2. Wind direction and speed during years 2003-2006. Data represents approximately $2 / 3$ of each year, with data only available in the warmer months $\left(T>-35 \mathrm{C}^{\circ}\right)$.

\section{Results and discussion}

\subsection{Absorption coefficient and sector control}

Throughout the field campaign at Summit, Greenland in the summer of 2006, the need for a sector control system to protect multi-day integrated samples was readily apparent. Sampling time periods flagged for contamination concern were often associated with brief extreme spikes in the absorption 


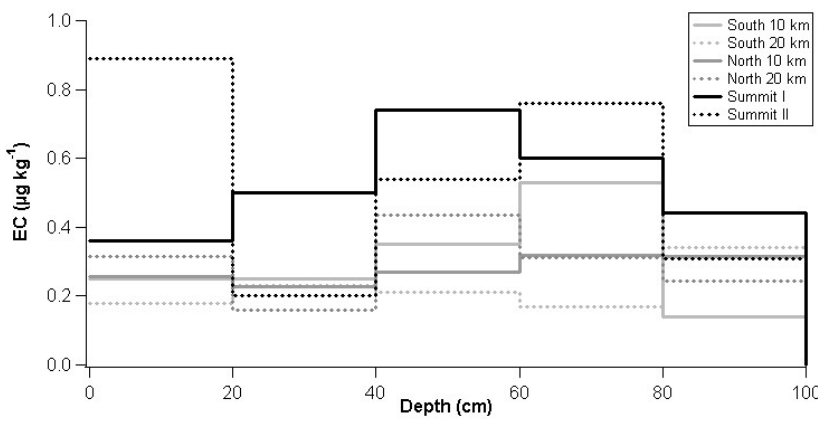

Fig. 3. Snow phase elemental carbon concentration in 1-m snow pits near and far from Summit, Greenland.

coefficient, reaching up to $30 \mathrm{Mm}^{-1}$, a factor of 200 higher than the summertime average of $0.15 \mathrm{Mm}^{-1}$ (Fig. 1). Additionally, it appears that the sector control wind speed and direction parameters selected were effective, with every major concentration spike coinciding with a "flag/shut-off" time period (Fig. 1). Thus, it is expected that previously reported filter measurements for carbonaceous particulate matter (Hagler et al., 2007b) are free from any major camp contamination.

Altogether, sector control flagged $21 \%$ of the sampling time during 26 May-18 July 2006. During this time period, the majority of the shut-down time was due to wind direction rather than wind speed as stagnant conditions (wind speed $<0.5 \mathrm{~m} \mathrm{~s}^{-1}$ ) were rare $(<5 \%$ of the summer). Using the available wind data for years 2003-2006 (Fig. 2), it can be seen that wind directions are generally dominated by southerly and moderate-speed winds. Applying the same sector control criteria over this longer period of time, wind direction ( $>288$ or $<45$ degrees) and low wind speed would lead to an approximate $15 \%$ and $4 \%$ shut-off time, respectively. Together, the sector control parameters applied to 2003-2006 would have induced a total 19\% loss in sampling time, similar to our summer 2006 experience. Therefore, the long-term use of a sector-control system to support sampling atmospheric species that may be contaminated by Summit camp emissions is expected to result in a $\sim 20 \%$ loss of sampling time. Given that the wind angle criteria used to "flag" time periods is very conservative and ongoing efforts to reduce emission source strength and spatial extent in the future, this estimated loss of sampling time should be considered as a high estimate. In fact, it can be seen that summer 2006 camp-related $\sigma_{\text {ap }}$ spikes occurred during only a fraction of the sector-controlled time, constituting $1.6 \%$ of the total sampling period (Fig. 1). This demonstrates that a higher precision sector control system would likely cause only minor interruptions in ambient sampling.

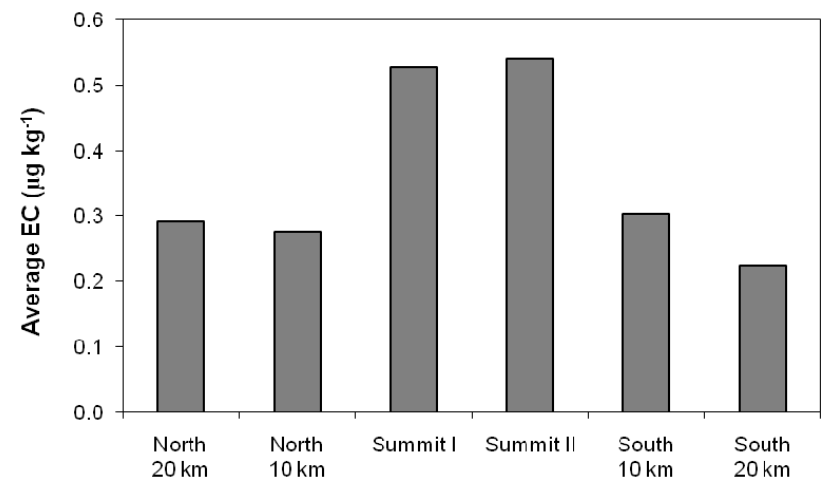

Fig. 4. 1-m snow pit average concentration of elemental carbon.

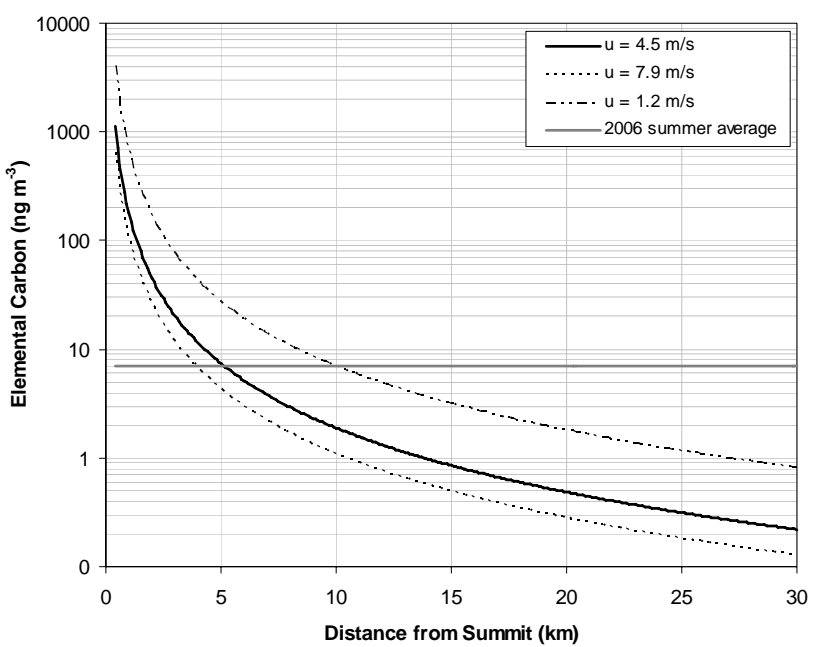

Fig. 5. Calculated plume centerline concentration over distance from camp, for the case of average wind speed and $+/-1$ standard deviation. The ambient EC concentration measured during the 2006 summer field campaign is shown as a reference.

\subsection{Snow pits}

In order to evaluate the footprint of Summit Camp emissions on surrounding snow, a series of 1-m snow pits were dug and sampled in the clean air sector of Summit and at distances up to $20 \mathrm{~km}$ north and south of camp (Table 1). Assessing the snow pit profiles, the two co-located snow pits near Summit Camp appear to be at a generally higher EC concentration than those located at $10 \mathrm{~km}$ or further from camp (Fig. 3). Given the coarseness of sampling ( $20 \mathrm{~cm}$ increments) and the difficulty in precisely collecting identical snow layers across multiple pits, a more clear way to compare the snow pit concentrations is to average over the entire depth sampled. In terms of the average EC concentration per pit, a marked difference between the Summit Camp snow pits and those at remote sites is observed (Fig. 4). The average EC concentration of the Summit Camp pits $\left(0.53 \mu \mathrm{g} \mathrm{kg}^{-1}\right.$ snow $)$ is a factor of 1.8-2.4 higher than EC levels in snow sampled at 
Table 1. 1-m snow pit locations near Summit, Greenland.

\begin{tabular}{lll}
\hline Snow pit description & Date sampled & Coordinates \\
\hline 20 km North of Summit & 26 June 2006 & $\mathrm{N} 72^{\circ} 44^{\prime}, \mathrm{W} 38^{\circ} 12^{\prime}$ \\
10 km North of Summit & 25 June 2006 & $\mathrm{N} 72^{\circ} 40^{\prime}, \mathrm{W} 38^{\circ} 26^{\prime}$ \\
Summit Camp I, in clean air sector & 20 June 2006 & $\mathrm{N} 72^{\circ} 34^{\prime}, \mathrm{W} 38^{\circ} 27^{\prime}$ \\
Summit Camp II, in clean air sector & 22 June 2006 & $\mathrm{N} 72^{\circ} 34^{\prime}, \mathrm{W} 38^{\circ} 27^{\prime}$ \\
10 km South of Summit & 29 June 2006 & $\mathrm{N} 72^{\circ} 30^{\prime}, \mathrm{W} 38^{\circ} 40^{\prime}$ \\
20 km South of Summit & 3 July 2006 & $\mathrm{N} 72^{\circ} 24^{\prime}, \mathrm{W} 38^{\circ} 39^{\prime}$ \\
\hline
\end{tabular}

10 and $20 \mathrm{~km}$ away from camp. One possible explanation of the higher EC measured near Summit Camp is a difference in snow accumulation rates near and far from the research station. However, past research indicates that this is likely only a minor factor; the snow accumulation rate reported at Summit was nearly identical to that at a location $28 \mathrm{~km}$ from Summit (Dibb and Fahnestock, 2004). The higher EC loading found closer to Summit suggests that future snow pit sampling for species believed to also have camp sources, or secondarily affected by camp pollution, should be performed at some distance from Summit. As snow pits at $20 \mathrm{~km}$ are at a similar EC concentration to those at $10 \mathrm{~km}$, it appears that the footprint of Summit is confined to within $10 \mathrm{~km}$. In addition, the average EC concentration in the snow pits north of Summit camp $\left(0.28 \mu \mathrm{g} \mathrm{kg}^{-1}\right)$ is not substantially higher than that found in the snow pits to the south of Summit $\left(0.26 \mu \mathrm{g} \mathrm{kg}^{-1}\right)$, suggesting that the increased camp activity during southerly winds does not translate to long-distance impacts on snow concentrations.

Given the difference in camp vs. distant (10 or $20 \mathrm{~km})$ snow pits, one conclusion is that our past reported carbonaceous snow concentrations (Hagler et al., 2007a,b) may have contamination issues. While no absolute guarantee can be placed on the trace level measurements reported, both the $\sigma_{\mathrm{ap}}$ data presented here and the nature of the reported snow concentrations give some support that our prior research findings remain unchanged. First, it should be noted that all snow concentrations previously reported (Hagler et al., 2007a,b) were at a satellite location twice the distance $(1 \mathrm{~km}$ from Summit Camp) as the 1-meter snow pits discussed here. This alone reduces the likelihood of significant camp impact. Next, as shown in Fig. 1, concentrated local plumes tend to be uncommon, short-lived, and higher than background concentrations by orders of magnitude. In the rare event that precipitation coincides with a concentrated plume, one would expect surface snow concentrations to similarly increase by orders of magnitude. In our surface snow time series collected in 2006 (Hagler et al., 2007b), very thin surface layers were collected and no orders-of-magnitude concentration spikes were observed. Thus, it is not expected that the summer 2006 surface snow samples suffered any substantial camp impact. This is an important point, as a major conclusion was based upon assessing buried summer layers in a 3-m snow pit relative to the surface snow (Hagler et al., 2007a).

Determining potential contamination of layers in the 3meter snow pit data (Hagler et al., 2007b) is more challenging, as a rare thin layer of contaminated snow would likely be diluted by non-contaminated snow in a relatively thick sample layer $(10-20 \mathrm{~cm})$. One simple comparison is to compare the top 1-m average of our 3-meter pit $\left(0.35 \mu \mathrm{g} \mathrm{kg}^{-1}\right)$ at the satellite site to the $1-\mathrm{m}$ pits closer to camp $\left(0.53 \mu \mathrm{g} \mathrm{kg}^{-1}\right)$, finding concentrations $34 \%$ lower and much closer to the range of the distant snow pits $\left(0.23-0.30 \mu \mathrm{g} \mathrm{kg}^{-1}\right)$. This is only a rough comparison, as the $3-\mathrm{m}$ and $1-\mathrm{m}$ snow pits were sampled approximately one month apart. Another strategy is to assess layer-by-layer patterns in the 3-m pit - it appears that nearly every layer with an EC increase (decrease) in concentration has a corresponding increase (decrease) in the potassium ion $\left(\mathrm{K}^{+}\right)$within an error margin of one layer (Hagler et al., 2007a). As $K^{+}$is a known tracer for biomass burning, these results suggest that a long-distance source was controlling the EC levels in the snow pit. One wintertime snow pit layer stands out as an exception $(120-130 \mathrm{~cm})$, in which EC increases and $\mathrm{K}^{+}$remains low, which may suggest a contamination concerns. As the 2006 snow pit analysis mainly focused on summertime snow layers (Hagler et al., 2007a), the findings are expected to be trustworthy.

\subsection{Gaussian plume modeling}

To further understand the air sampling and snow pit results, we estimated the transport of Summit camp plumes to the surrounding snow using a Gaussian plume model. This model was selected because the Summit camp diesel generators are co-located and can be considered as continuous point-source emissions, a situation appropriate for Gaussian plume modeling. For each hourly meteorological data point available over years 2003-2006, the ambient EC concentration was calculated as a function of distance and direction from camp. Looking at the worst case scenario of a centerline plume concentration, it can be seen that for the typical range of wind speeds very high EC concentrations $\left(>1000 \mathrm{ng} \mathrm{m}^{-3}\right)$ are estimated within close proximity 
a.

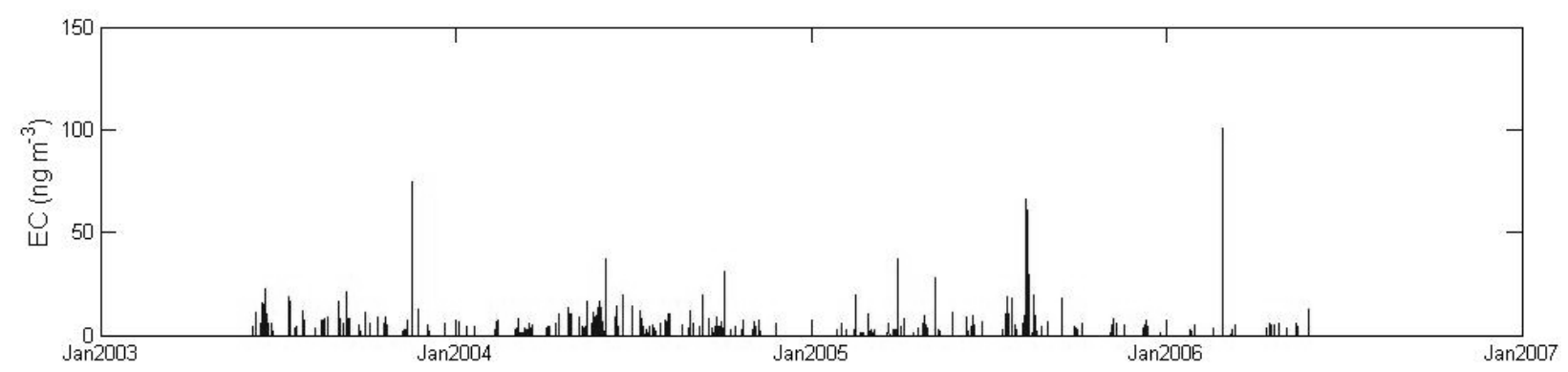

b.

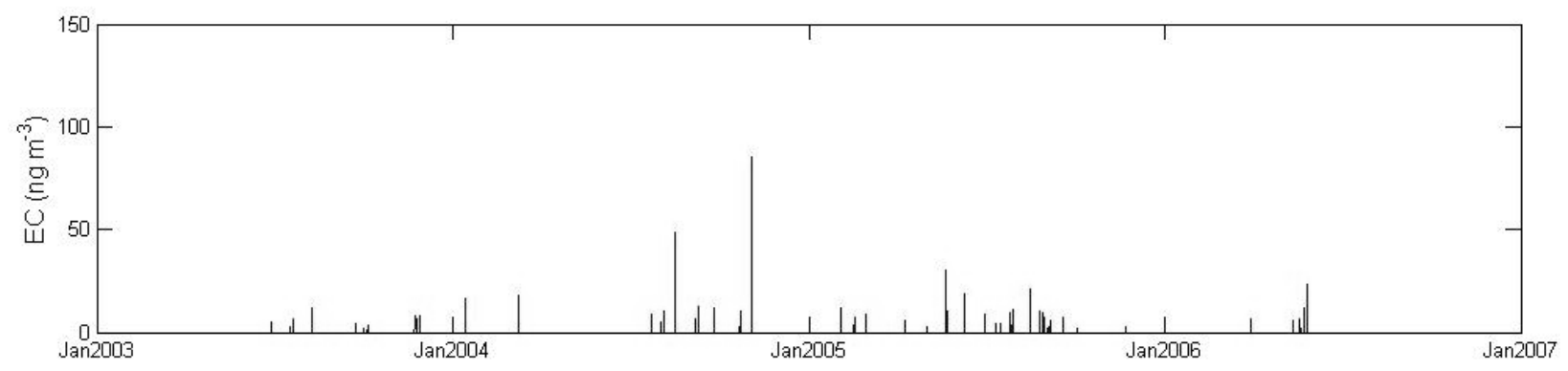

Fig. 6. Estimated contribution from camp to atmospheric elemental carbon at a distance of $10 \mathrm{~km}$ from Summit Camp for (a) wind direction 140-145 degrees (plumes heading NW of camp) and (b) wind direction of 325-330 degrees (plumes heading SE of camp).

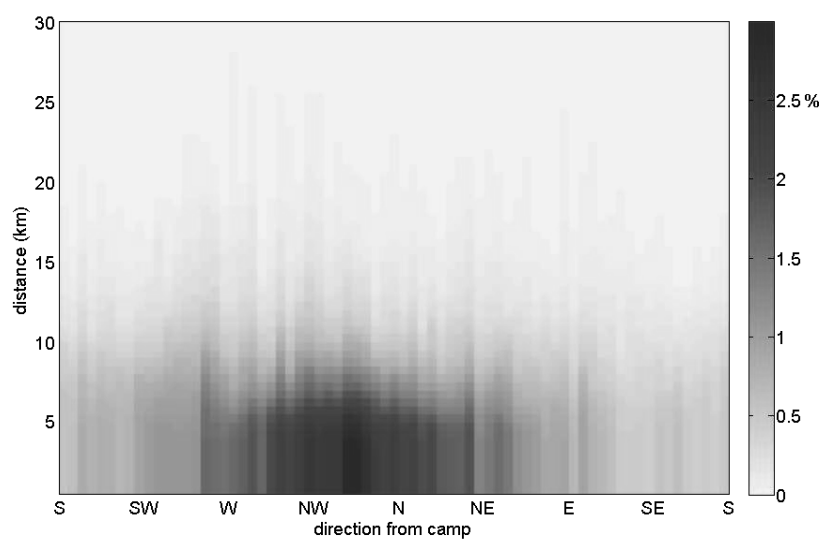

Fig. 7. Estimated fraction of time (\%) that camp contribution at a specific angle and distance will exceed the 2006 measured average $\mathrm{EC}\left(7 \mathrm{ng} \mathrm{m}^{-3}\right)$.

to camp, dropping rapidly within the first few kilometers of distance (Fig. 5). Using the sector-controlled summer 2006 average concentration of EC of $7 \mathrm{ng} \mathrm{m}^{-3}$ (Hagler et al., 2007b) as a reference point, it can be seen that for the average wind speed camp contribution to ambient EC falls below the 2006 average at $5 \mathrm{~km}$ from camp, or to $10 \%$ of the 2006 average at approximately $16.5 \mathrm{~km}$. However, for lower (higher) speed winds, it can be seen that the lesser (greater) dispersion leads to a slower (faster) decline in EC concentra- tions and a need to travel $\sim 30 \mathrm{~km}(12.5 \mathrm{~km})$ to reach the $10 \%$ contribution level.

While camp plumes can pose a major contamination threat if directly passing over a sampling area, it is important to keep in mind the relative frequency of camp impact in any one direction. At $10 \mathrm{~km}$ in the northwest direction of camp, prevailing winds lead to frequent concentration spikes over years 2003-2006 (Fig. 6a). In the opposite direction, model results show that camp-related concentration spikes are still evident but far fewer in number (Fig. 6b). As snow contamination for particulate species are mainly controlled by the occurrence of wet deposition events (Bergin et al., 1995), not all atmospheric concentration spikes are expected to translate to snow contamination. However, a greater frequency of camp plumes traveling in a certain direction certainly increases the risk of sample contamination.

In order to determine "safe" distances and angles for future field work near Summit, the frequency of major camp plume events (i.e. camp contribution exceeding summer 2006 average EC concentrations) is modeled over all angles and at distances up to $30 \mathrm{~km}$ from camp (Fig. 7). It appears that the highest risk of significant camp impact (3\% of the time for a given 5 degree angle bin) occurs at a close proximity to camp $(0.5 \mathrm{~km})$ in the northwest to north direction of camp. Meanwhile, the southeast direction receives significant camp impact at $0.5 \mathrm{~km}$ only $\sim 1 \%$ of the time over a given 5 degree angle. In addition, it is clear that moving further in distance from camp lessens risk at all directions from camp. At $10 \mathrm{~km}$ 
and $20 \mathrm{~km}$ from camp, the maximum (minimum) frequency of significant camp impact reduces to about $1 \%(0.2 \%)$ and $0.2 \%(0.05 \%)$ of the time, respectively. Although there are a number of assumptions influencing the Gaussian plume model estimates, it is interesting that the model results are in a similar range of the summer 2006 observed frequency of camp-related $\sigma_{\text {ap }}$ spikes $(1.6 \%)$ at $\sim 1 \mathrm{~km}$ southwest of Summit Camp. In interpreting the model results, it is important to point out that the estimated impact of camp contamination depends not only on the camp emission rate but also the typical ambient concentration of the species of interest. Also, it should be noted that the model does not take into account the increased camp activity during southerly winds, which may lead to more highly concentrated plumes transported northward.

In general, the Gaussian plume modeling results support the insignificant difference in average EC concentrations between snow pits located at $10 \mathrm{~km}$ vs. $20 \mathrm{~km}$ and North vs. South. Since the frequency of significant camp contamination is already reduced to $<1 \%$ of the time per 5 degree angle bin over all directions (Fig. 7), the distant 1-meter snow pits (equal to $\sim 1$ year of snowfall) likely avoided a major camp plume event. The model also indicates that snow contamination at $1 \mathrm{~km}$ distance even in the "clean air sector" south of camp is more likely than any point $>10 \mathrm{~km}$ away given the more highly concentrated plumes close to camp.

\section{Conclusions}

In all remote and pristine sampling environments, the impact of research site activities on the local environment needs to be taken into consideration to ensure the accuracy of field measurements. At Summit, Greenland, it appears that camp emissions can greatly impact nearby EC concentrations in the air and snow. Extreme and short-term spikes in the absorption coefficient occurred numerous times throughout the summer of 2006 during time periods that were flagged by a sector control system warning of potential approaching camp plumes. For atmospheric samples, it appears that a sector control system would be a successful means of avoiding camp combustion-related pollution. While longer-term sampling may have a reduction in sampling time by $\sim 20 \%$ (conservative estimate), loss in sample time for shorter field studies will heavily depend on wind patterns and thus may have a considerably higher or lower fraction of down-time compared to the long-term estimate.

In terms of snow sampling, Gaussian plume modeling and snow pit results point to a distance of approximately $10 \mathrm{~km}$ towards the southeast as a good "rule of thumb" to minimize risk of camp impact $(0.2 \%$ frequency of significant camp plume events). To translate this result to other species potentially impacted by camp generator emissions (e.g. specific organic molecules, isotopes of carbon or nitrogen, sulfate), one needs to consider the generator emission rate of a par- ticular species relative to its expected ambient background concentration. Given a lower generator emission rate and/or higher background concentration compared to EC, the "safe" distance may be closer to Summit camp; and, the converse would be true given a higher emission rate and/or lower background concentrations.

While integrating sector control systems into atmospheric studies and traveling far distances to perform snow sampling can improve the quality of field sampling at Summit, a reduction in camp emissions would be a second (and preferable) means to reduce the anthropogenic footprint at such a remote location. A greater reliance on non-emitting power sources (e.g. wind or solar) may be potential technologies to consider, as well as improved energy efficiency in camp structures and fuel-powered vehicles.

Acknowledgements. The authors are grateful for access to meteorological data from ETH Zürich, Institute for Atmospheric and Climate Science and for the field support and detailed information on camp power generation from Veco Polar Resources. We thank the New York Air National Guard 109 Airlift Wing for transport of goods and personnel to Summit, Greenland. Financial support for this research came from the National Science Foundation and graduate fellowships to the author (G.H.) from the American Association of University Women and P.E.O. International. We also wish to thank Casey Anderson and Rob Griffin of University of New Hampshire and Erika von Schneidemesser, Martin Shafer, and Jamie Schauer of University of Wisconsin-Madison for their planning contributions and field support for this project.

Edited by: V. F. McNeill

\section{References}

Bergin, M. H., Jaffrezo, J.-L., Davidson, C. I., Dibb, J. E., Pandis, S. N., Hillamo, R., Maenhaut, W., Kuhns, H. D., Makela, T.: The contributions of snow, fog, and dry deposition to the summer flux of anions and cations at Summit, Greenland, J. Geophys. Res., 100(D8), 16 275-16 288, doi:10.1029/95JD01267, 1995.

Dibb, J. E., and Fahnestock, M.: Snow accumulation, surface height change, and firn densification at Summit, Greenland: Insights from 2 years of in situ observation, J. Geophys. Res., 109, D24113, doi:10.1029/2003JD004300, 2004.

Hagler, G. S. W., Bergin, M. H., Smith, E. A., Dibb, J. E., Anderson, C., Steig, E. J.: Particulate and water-soluble carbon measured in recent snow at Summit, Greenland, Geophys. Res. Lett., 34, L16505, doi:10.1029/2007GL030110, 2007a.

Hagler G. S. W., Bergin, M. H., Smith, E. A., Dibb, J. E.: A summer time series of particulate carbon in the air and snow at Summit, Greenland, J. Geophys. Res., 112, D21309, doi:10.1029/2007JD008993, 2007b.

US EPA OAQPS: User's Guide for the Industrial Source Complex (ISC3) Dipersion Models, Vol. II-Description of Model Algorithms, EPA-454/B-95-003b (http://www.epa.gov/scram001/ userg/regmod/isc3v2.pdf, accessed 7 February 2007), 1995. 